\title{
Oral thyroxin supplementation in infants undergoing cardiac surgery: A double-blind placebo-controlled randomized clinical trial
}

\author{
Sachin Talwar, MCh, Amolkumar Bhoje, MS, Rajesh Khadagawat, DM, Pradeep Chaturvedi, MD, \\ Vishnubhatla Sreenivas, PhD, Neeti Makhija, MD, Manoj Sahu, DM, Shiv Kumar Choudhary, MCh, and \\ Balram Airan, MCh
}

\section{ABSTRACT}

Background: Decreases in serum total thyroxin and total triiodothyronine occurs after cardiopulmonary bypass, and is reflected as poor immediate outcome. We studied effects of oral thyroxin supplementation in infants who underwent open-heart surgery.

Methods: In this prospective study, 100 patients were randomized into 2 groups: 50 in the thyroxin group $(\mathrm{TH})$ and 50 in the placebo group (PL). Patients in the TH group received oral thyroxin $(5 \mu \mathrm{g} / \mathrm{kg}) 12$ hours before surgery and once daily for the remainder of their intensive care unit (ICU) stay. Data on intraoperative and postoperative variables were recorded. Cardiac index (CI) was measured. Perioperative serum thyroid hormone levels and serum interleukin-6 and tumor necrosis factor- $\alpha$ were measured. Secondary analysis was performed by dividing patients into simple and complex subcategories.

Results: Results of the primary analysis indicated a higher CI in the TH compared with the PL. In the complex category, the mean duration of mechanical ventilation was $3.85 \pm 0.93$ and $4.66 \pm 1.55$ days in the TH and PL, respectively $(P=.001)$. Mean ICU stay was $6.79 \pm 2.26$ and $8.33 \pm 3.09$ days $(P=.03)$, and mean hospital stay was $15.70 \pm 4.77$ and $18.90 \pm 4.48$ days $(P=.01)$ in the TH and PL, respectively. There were no significant differences between the TH and the PL in the simple category. CI was higher in the TH at all time points $(P=.004)$. The average therapeutic intervention scoring system scores for the first 2 days were higher in the PL in the complex category.

Conclusions: Oral thyroxin supplementation improves the CI and reduces the inotropic requirement. In addition, it reduces the duration of mechanical ventilation, ICU and hospital stay, and therapeutic intervention scoring system in infants after surgery for complex congenital heart defects. (J Thorac Cardiovasc Surg 2018;156:1209-17)

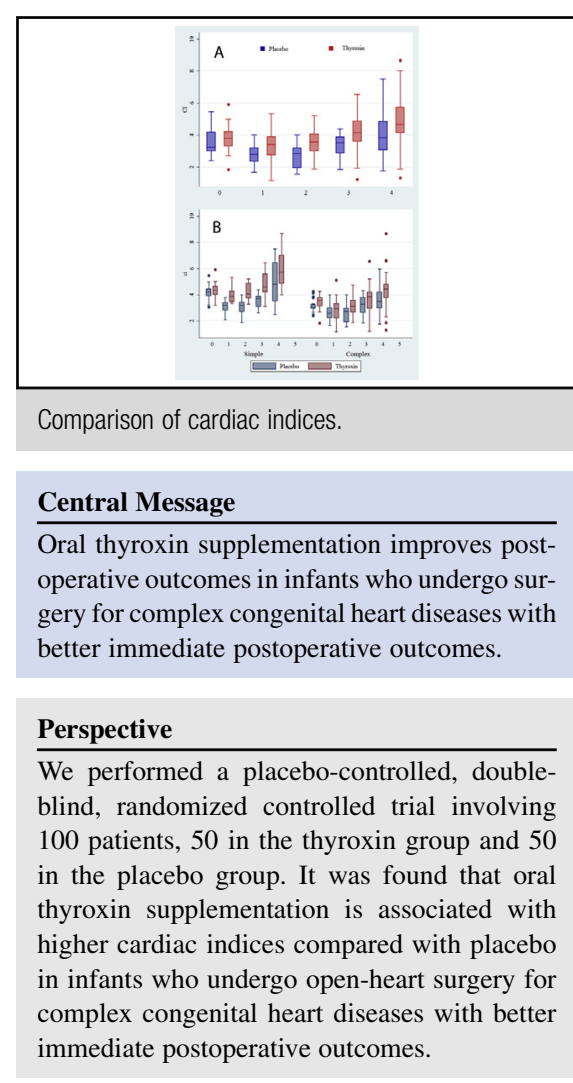

See Editorial Commentary page 1218.

See Editorial page 1207.
Thyroid hormones regulate every aspect of the cardiovascular system. A decrease in thyroid hormone levels is

\footnotetext{
From the Cardiothoracic Center, All India Institute of Medical Sciences, New Delhi, India

Read at the 96th Annual Meeting of The American Association for Thoracic Surgery, Baltimore, Maryland, May 14-18, 2016.

Received for publication June 14, 2016; revisions received May 7, 2018; accepted for publication May 13, 2018.

Address for reprints: Sachin Talwar, MCh, Department of Cardiothoracic and Vascular Surgery, All India Institute of Medical Sciences, New Delhi 10029, India (E-mail: sachintalwar@hotmail.com).

$0022-5223 / \$ 36.00$

Copyright (C) 2018 by The American Association for Thoracic Surgery

https://doi.org/10.1016/j.jtcvs.2018.05.044
}

observed after cardiopulmonary bypass (CPB) in children who undergo open-heart surgery. ${ }^{1}$ The decrease in thyroid hormone levels after CPB is more profound in neonates and infants compared with adults. This makes them vulnerable to the harmful effects of a CPB-induced temporary hypothyroid state. ${ }^{2}$ Nonpulsatile flow to the brain depressing

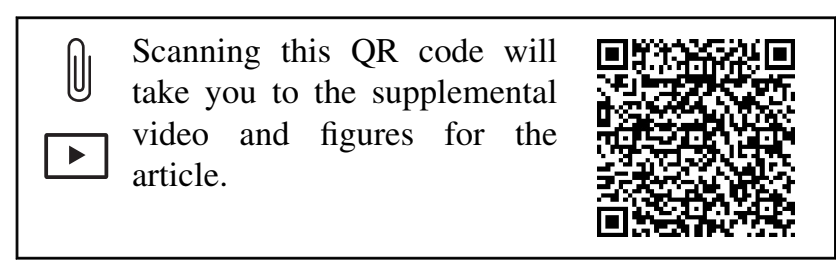




$$
\begin{aligned}
& \text { Abbreviations and Acronyms } \\
& \begin{aligned}
\text { CI } & =\text { cardiac index } \\
\text { CPB } & =\text { cardiopulmonary bypass } \\
\text { ICU } & =\text { intensive care unit } \\
\text { IL } & =\text { interleukin } \\
\text { IS } & =\text { inotropic score } \\
\text { LCOS } & =\text { low cardiac output syndrome } \\
\text { T4 } & =\text { thyroxin } \\
\text { TISS } & =\text { therapeutic intervention score } \\
\text { TT3 } & =\text { total triiodothyronine } \\
\text { TT4 } & =\text { total thyroxin }
\end{aligned}
\end{aligned}
$$

the hypothalamus-pituitary-thyroid axis, hypothermia, hemodilution, and ultrafiltration during CPB have been identified to be responsible for a decrease in thyroid hormone levels after $\mathrm{CPB} .{ }^{3}$ These hormones regulate cardiac output by their effects on heart rate, cardiac contractility, and systemic vascular resistance, ${ }^{4}$ with lower levels being associated with poor postoperative outcomes. ${ }^{1,5}$ We conducted a double-blind placebo-controlled prospective randomized study to assess the efficacy of oral thyroxin (T4) supplementation in infants who underwent open-heart surgery.

\section{METHODS}

This prospective, double-blind, placebo-controlled randomized trial was conducted at the Cardiothoracic Sciences Center of the All India Institute of Medical Sciences, New Delhi, India, between April 2014 and July 2015. The study protocol was approved by the Institute Ethics Committee (IEC/ NP-235 and RP-14/17.06.03) and the study protocol was duly registered with the clinical trials registry of India (CTRI/03/058263). Informed consent was obtained from the parents/guardians of all of the patients. We aimed to evaluate the effects of oral T4 supplementation in infants 6 months of age or younger, who underwent open-heart surgery with CPB. The primary end point was change in the cardiac index $(\mathrm{CI})$. The secondary end points were change in inotropic score (IS), and levels of serum inflammatory markers. Clinical end points were time to extubation, intensive care unit (ICU) stay, and occurrence of low cardiac output syndrome (LCOS), which was defined as per standard criteria that include subjective determination of reduced peripheral perfusion, diminishing urine output, and increasing lactate levels with acidosis, and hemodynamic instability despite optimal inotropic support. ${ }^{1}$ In the absence of data on mixed venous saturations, a rising lactate level was used as a surrogate for occurrence of LCOS.

The study population was further stratified into complex and simple categories for purposes of secondary analysis and to clarify the differences between the 2 groups of patients that exhibited different intraoperative and postoperative behavior. The simple category included 38 patients and the complex category included 62 patients. The complex category consisted of 56 patients with dextra-transposition of the great arteries ( 20 with intact ventricular septum and 36 with associated ventricular septal defect), 3 with tetralogy of Fallot, 2 with total anomalous pulmonary venous connection, and 1 with truncus arteriosus. The simple category consisted of patients with varying types of ventricular septal defects.

\section{Sample Size and Randomization}

In our experience, the preoperative $\mathrm{CI}$ in the patients in this study is expected to be $3.5 \mathrm{~L} / \mathrm{min} / \mathrm{m}^{2}$. We expect an average improvement/change in the CI of $0.4 \mathrm{~L} / \mathrm{min} / \mathrm{m}^{2}$. Assuming this increases by $1 \mathrm{~L} / \mathrm{min} / \mathrm{m}^{2}$ in the thyroid group, with a common SD of $1 \mathrm{~L} / \mathrm{min} / \mathrm{m}^{2}$, we require 44 patients in each of the placebo and T4 groups to detect this difference to be statistically significant in a 2 -sided test with $5 \% \alpha$ error and $80 \%$ power. Giving an allowance for attrition, a sample size of 50 was chosen in each group. The number of patients in the simple and complex groups were not defined beforehand for calculation of the sample size. A randomization list was generated using the nQuery advisor version 7.0 (Statistical Solutions Ltd, Cork, Ireland). We used stratified randomization with blocks of 4 separately for the simple and complex groups to have an even distribution between the patients with different severities of diagnosis. This randomization sequence was transferred to sealed envelopes, which were opened just before administering T4/placebo (Figure E1).

\section{T4 Administration and Dosage}

Preoperative thyroid hormone levels were tested on an outpatient basis and patients with abnormal values were excluded from the study. The patients were allocated to either the drug A (T4) or drug B (placebo) group using random number allocation in sealed covers. The preparation of the drug/ placebo was performed by a person who labeled them as A or B and handed it over to another person who was blinded to the contents of the drug and was responsible for the storage, maintenance, and administration. To prepare the drug, 1 tablet of Eltroxin (containing $25 \mu \mathrm{g}$ of levothyroxine sodium; GlaxoSmithKline Pharmaceuticals Ltd, Mumbai, India) was crushed and dissolved in $5 \mathrm{~mL}$ of saline so that the concentration of levothyroxine was $5 \mu \mathrm{g} / \mathrm{mL}$. The placebo was prepared by dissolving an identical plain sugar tablet in $5 \mathrm{~mL}$ saline. The calculated dose of the drug was $5 \mu \mathrm{g} / \mathrm{kg}$ body weight per dose or $1 \mathrm{~mL} / \mathrm{kg}$ of the prepared solution. The assigned solution was administered in such a dose that patients in the test group received 1 dose equivalent to $5 \mu \mathrm{g} / \mathrm{kg}$ of levothyroxine sodium 12 hours before surgery. This dose was repeated once daily at $7 \mathrm{Am}$ for the duration of the remaining ICU stay via a nasogastric tube. The control group received placebo in a similar fashion. All babies received similar standard preanesthetic medication and were breastfed up to 4 hours before surgery.

\section{Anesthesia Technique}

The anesthesia technique was standardized for all patients. Intravenous induction with ketamine $2 \mathrm{mg} / \mathrm{kg}$, fentanyl $2 \mu \mathrm{g} / \mathrm{kg}$, and rocuronium $1 \mathrm{mg} /$ $\mathrm{kg}$ was used. Sevoflurane with air and oxygen was used for maintenance to maintain a minimum alveolar concentration of 0.8 to 1 . Midazolam $0.1 \mathrm{mg} /$ $\mathrm{kg}$, fentanyl $0.1 \mu \mathrm{g} / \mathrm{kg}$, and vecuronium $0.1 \mathrm{mg} / \mathrm{kg}$ were used intermittently. Heparin $(3 \mathrm{mg} / \mathrm{kg})$ was administered and supplemented as required to maintain an active clotting time of 480 seconds or greater on CPB.

\section{Surgical Technique}

Before making the skin incision, venous blood samples were taken in a plain vial. CI was measured using noninvasive impedance cardiometry method with an ICON monitor (ICON Osypka Medical GmBH, Berlin, Germany). ${ }^{6}$ ICON is an electrical cardiometry principle-based noninvasive technology to compute cardiac output. Four electrodes are placed on the skin ( 2 on the left side of the neck, one below the other, the third on the left midaxillary line at the level of the xiphisternum, and the fourth $2 \mathrm{~cm}$ below the third). These electrodes sense the electrical impedance of red blood cells and it is converted into CI by computer software. In infants with a short neck, the first electrode was placed on the forehead and the fourth one on the left femoral region whereas the position of the second and third were same as for other babies. The validity and reliability of this method of determination of CI has been proven by comparing it with a standard invasive method using a pulmonary artery catheter. This has been shown to be an accurate method of calculating the $\mathrm{CI}$ in previous studies from our institution (https://pdfs.semanticscholar.org/d837/ 133b554ac4a5e4bede29d75bef68f5612772.pdf). ${ }^{6-8}$

After median sternotomy, standard hypothermic $\left(28^{\circ} \mathrm{C}-32^{\circ} \mathrm{C}\right) \mathrm{CPB}$ was established after aortobicaval cannulation using a nonpulsatile roller pump, 
membrane oxygenator, and standard extracorporeal circuits. The CPB circuit was primed with fresh blood as per standard criteria, with Plasma-Lyte A (Baxter, Deerfield, Ill), as needed. Heparin, mannitol, and sodium bicarbonate were added to the circuit as needed. CPB was carried out at flow rates of 150 to $200 \mathrm{~mL} / \mathrm{kg} / \mathrm{min}$ with cooling at a rate of $1^{\circ} \mathrm{C}$ per minute and rewarming at the rate of $1^{\circ} \mathrm{C}$ every 3 minutes. A single dose of del Nido cardioplegia $(20 \mathrm{~mL} / \mathrm{kg}$ ) was administered into the aortic root. Topical cooling with cold saline solution was used. A hemofilter was always incorporated into the CPB circuit and conventional ultrafiltration was carried out in all patients. Modified ultrafiltration was not carried out in any patient. Surgical procedures were performed in a standard fashion. Dobutamine $(5 \mu \mathrm{g} / \mathrm{kg} / \mathrm{min})$ and nitroglycerine $(0.5 \mu \mathrm{g} / \mathrm{kg} / \mathrm{min})$ were started electively in all patients before terminating CPB. Hypotension was managed by optimizing fluid status and/or noradrenaline $(0.05 \mu \mathrm{g} / \mathrm{kg} /$ $\mathrm{min})$. Adrenaline infusion was started depending upon the cardiac contractility. After termination of CPB, the CI was again measured. Two hours after terminating $\mathrm{CPB}, 2 \mathrm{~mL}$ of plain blood sample was obtained.

\section{Postoperative Care}

In the ICU, the same team members who were blinded to the patient group provided standard care to all patients. Postoperatively, parameters assessed were cardiac rhythm, inotropic requirement, duration of mechanical ventilation, CI at 6,12 , and 24 hours, and occurrence of LCOS as previously described. Serum lactate levels were measured at 4 time points: at completion of surgery, 2 hours later, 6 hours later, and 24 hours later. All patients had serial transthoracic echocardiograms before being discharged from the ICU for assessment of adequacy of repair and ventricular function. Inotropic requirement was assessed in terms of IS ${ }^{9}$ : IS for the first 24 hours, 25 to 48 hours, 49 to 72 hours, 73 to 96 hours, and 96 to 120 hours using the formula ${ }^{9}$ :

$$
\begin{aligned}
\mathrm{IS}= & \text { dopamine dose }(\mu \mathrm{g} / \mathrm{kg} / \mathrm{min})+\text { dobutamine dose }(\mu \mathrm{g} / \mathrm{kg} / \mathrm{min}) \\
& +100 \times \text { epinephrine dose }(\mu \mathrm{g} / \mathrm{kg} / \mathrm{min}) \\
& +10 \times \text { milrinone dose }(\mu \mathrm{g} / \mathrm{kg} / \mathrm{min}) \\
& +10,000 \times \text { vasopressin dose }(\mathrm{U} / \mathrm{kg} / \mathrm{min}) \\
& +100 \times \text { norepinephrine dose }(\mu \mathrm{g} / \mathrm{kg} / \mathrm{min}) .
\end{aligned}
$$

The therapeutic intervention score (TISS) was calculated for all patients for each nursing shift of 8 hours, for a maximum of 5 days. The TISS is an indicator of the logistics and manpower requirement in the ICU for managing individual patients and is described elsewhere. ${ }^{10} \mathrm{Com}-$ plications including LCOS, bleeding, arrhythmias, heart block, ventricular dysfunction, prolonged pleural effusions, infection, renal failure, respiratory infection requiring prolonged ventilator support, etc, were recorded.

\section{Estimation of Thyroid Hormone Profile}

All blood samples were separated and stored at $-40^{\circ} \mathrm{C}$ pending analysis. All thyroid hormone levels were analyzed using electrochemical luminescence immunoassay (ELISA) using Roche Elecsys 2010 immunoassay analyzer (Roche Diagnostics, Indianapolis, Ind). The measurements were made at 4 time points: pre-CPB, post- $\mathrm{CPB}, 24$ hours after $\mathrm{CPB}$, and 48 hours after termination of CPB and included: serum total T4 (TT4; normal range, 5.13-14.06 $\mu \mathrm{g} / \mathrm{dL}$ ), serum total triiodothyronine level (TT3; normal range, $0.84-2.02 \mathrm{ng} / \mathrm{mL}$ ), and serum thyroid stimulating hormone (normal range, $0.27-4.2 \mathrm{mIU} / \mathrm{mL}$ ).

\section{Estimation of Tumor Necrosis Factor- $\alpha$ and Interleukin-6}

Blood samples were collected at 4 time points: pre-bypass, post-bypass, 24 , and 48 hours after surgery. Serum was stored at $-80^{\circ} \mathrm{C}$ and the final biochemical analysis was made using ELISA with the Bio-Rad ELISA reader (Bio-Rad Laboratories Inc, Hercules, Calif).

\section{STATISTICAL ANALYSIS}

Statistical analysis was carried out using Stata 14.1 software (Stata Corp LP, College Station, Tex). Quantitative characteristics are presented as mean $\pm \mathrm{SD}$ and qualitative characteristics as proportion $(\%)$. Pre- versus postoperative comparisons of thyroid profile were performed using the paired $t$ test. Preoperative diagnoses were compared between the thyroid and placebo group using Fisher's exact test or $\chi^{2}$ test. Comparisons between thyroid and placebo groups were made using Student $t$ test. For variables suspected to be non-normal, the nonparametric Wilcoxon rank sum test was used. Clinical outcomes including LCOS, mechanical ventilation $>24$ hours, and death were compared between the groups using Fisher exact test. Area under the curve for individual thyroid parameters was calculated using the trapezoidal rule. A robust mixed effect modeling with unstructured covariance structure was carried out taking patient's effect as random. A group versus time interaction was tested for CI and IS. For outcomes that were not the prime focus of interest or were not significant in simple analysis, the time versus T4 effect between simple and complex categories was not analyzed. A $P$ value of $<.05$ was considered as statistically significant.

\section{RESULTS}

\begin{tabular}{|c|c|c|c|c|c|c|c|c|c|}
\hline Characteristic & $\begin{array}{c}\text { Thyroxin } \\
\text { total } \\
(\mathbf{n}=\mathbf{5 0})\end{array}$ & $\begin{array}{c}\text { Placebo } \\
\text { total }(\mathbf{n}=\mathbf{5 0})\end{array}$ & $P$ & $\begin{array}{l}\text { Thyroxin } \\
\text { complex } \\
(\mathbf{n}=\mathbf{3 0})\end{array}$ & $\begin{array}{l}\text { Placebo } \\
\text { complex } \\
(n=32)\end{array}$ & $P$ & $\begin{array}{c}\text { Thyroxin } \\
\text { simple } \\
(n=20)\end{array}$ & $\begin{array}{c}\text { Placebo } \\
\text { simple } \\
(n=18)\end{array}$ & $P$ \\
\hline Age, mo & $2.50 \pm 1.14$ & $2.66 \pm 1.43$ & .54 & $2.08 \pm 1.06$ & $2.24 \pm 1.27$ & .59 & $3.12 \pm 0.99$ & $3.40 \pm 1.44$ & .49 \\
\hline Female sex, n $(\%)$ & $18(36)$ & $10(20)$ & .08 & $10(33)$ & $8(25)$ & .47 & $8(40)$ & $2(11)$ & .004 \\
\hline Weight, kg & $4.2 \pm 0.87$ & $4.1 \pm 0.91$ & .44 & $3.88 \pm 0.91$ & $3.73 \pm 0.77$ & .49 & $4.7 \pm 0.52$ & $4.70 \pm 0.81$ & .91 \\
\hline $\mathrm{BSA}, \mathrm{m}^{2}$ & $0.26 \pm 0.04$ & $0.26 \pm 0.04$ & .61 & $0.25 \pm 0.04$ & $0.25 \pm 0.40$ & .67 & $0.29 \pm 0.02$ & $0.29 \pm 0.03$ & .98 \\
\hline Complexity & 50 & 50 & .68 & 30 & 32 & - & 20 & 18 & - \\
\hline
\end{tabular}

The complexity of the diagnoses was equally distributed among the groups $(P=.84)$. There were no significant demographic differences between the 2 groups (Table 1).

TABLE 1. Demographic variables in patients stratified according to the complexity of diagnosis

$B S A$, Body surface area. 
TABLE 2. Perioperative variables in complex and simple categories

\begin{tabular}{|c|c|c|c|c|c|c|c|c|c|}
\hline \multirow[b]{2}{*}{ Variable } & \multicolumn{2}{|c|}{ Total } & \multirow[b]{2}{*}{$P$} & \multicolumn{2}{|c|}{ Complex } & \multirow[b]{2}{*}{$P$} & \multicolumn{2}{|c|}{ Simple } & \multirow[b]{2}{*}{$P$} \\
\hline & $\begin{array}{l}\text { Thyroxin } \\
(\mathbf{n}=\mathbf{5 0})\end{array}$ & $\begin{array}{l}\text { Placebo } \\
(\mathbf{n}=\mathbf{5 0})\end{array}$ & & $\begin{array}{l}\text { Thyroxin } \\
(\mathbf{n}=\mathbf{3 0})\end{array}$ & $\begin{array}{l}\text { Placebo } \\
(\mathbf{n}=32)\end{array}$ & & $\begin{array}{l}\text { Thyroxin } \\
(\mathbf{n}=20)\end{array}$ & $\begin{array}{l}\text { Placebo } \\
(\mathbf{n}=18)\end{array}$ & \\
\hline $\mathrm{CPB}$ time, minutes & $96.86 \pm 36.90$ & $99.94 \pm 34.79$ & .67 & $119.4 \pm 29.49$ & $113.18 \pm 22.23$ & .40 & $63.05 \pm 13.36$ & $75.33 \pm 39.82$ & .20 \\
\hline $\begin{array}{l}\text { AOCX time, } \\
\text { minutes }\end{array}$ & $63.30 \pm 27.71$ & $65.00 \pm 25.84$ & .75 & $81.60 \pm 18.27$ & $76.53 \pm 17.50$ & .27 & $35.85 \pm 12.22$ & $44.50 \pm 25.90$ & .19 \\
\hline Ultrafiltration, $\mathrm{mL}$ & $274.30 \pm 18.00$ & $250.38 \pm 93.55$ & .28 & $278.33 \pm 126.17$ & $260.37 \pm 100.35$ & .68 & $268.25 \pm 132.4$ & $232.61 \pm 79.61$ & .63 \\
\hline $\begin{array}{c}\text { Duration of } \\
\text { mechanical } \\
\text { ventilation }\end{array}$ & $\begin{array}{l}60.2 \pm 127.08 \mathrm{~h} \\
2.50 \pm 5.30 \mathrm{~d}\end{array}$ & $\begin{array}{l}75.68 \pm 57.01 \mathrm{~h} \\
31.53 \pm 2.37 \mathrm{~d}\end{array}$ & .13 & $\begin{array}{c}92.50 \pm 22.21 \mathrm{~h} \\
3.85 \pm 0.93 \mathrm{~d}\end{array}$ & $\begin{array}{c}111.81 \pm 37.30 \mathrm{~h} \\
4.66 \pm 1.55 \mathrm{~d}\end{array}$ & .001 & $\begin{array}{r}11.80 \pm 1.32 \mathrm{~h} \\
0.49 \pm 0.06 \mathrm{~d}\end{array}$ & $\begin{array}{r}11.44 \pm 1.69 \mathrm{~h} \\
0.48 \pm 0.70 \mathrm{~d}\end{array}$ & .47 \\
\hline LCOS, n (\%) & 11 & 17 & .18 & $8(26 \%)$ & $13(40 \%)$ & .25 & $3(15 \%)$ & $4(22 \%)$ & .57 \\
\hline $\mathrm{L}-0, \mathrm{mg} / \mathrm{dL}$ & $3.80 \pm 1.68$ & $4.00 \pm 1.00$ & .20 & $6.01 \pm 2.3$ & $7.12 \pm 1.19$ & .17 & 3.86. \pm 1.6 & $2.00 \pm 1.31$ & .90 \\
\hline $\mathrm{L}-1, \mathrm{mg} / \mathrm{dL}$ & $2.45 \pm 1.44$ & $2.26 \pm 0.97$ & .36 & $4.28 \pm 1.79$ & $4.16 \pm 1.80$ & .29 & $2.24 \pm 1.26$ & $2.00 \pm 1.56$ & .07 \\
\hline $\mathrm{L}-2, \mathrm{mg} / \mathrm{dL}$ & $2.00 \pm 1.20$ & $1.87 \pm 1.19$ & .25 & $2.71 \pm 2.00$ & $2.84 \pm 1.63$ & .64 & $1.96 \pm 1.18$ & $2.00 \pm 1.30$ & .36 \\
\hline $\mathrm{L}-3, \mathrm{mg} / \mathrm{dL}$ & $1.85 \pm 1.58$ & $1.95 \pm 1.29$ & .82 & $2.21 \pm 1.35$ & $2.37 \pm 1.89$ & .19 & $1.758 \pm 0.97$ & $2.00 \pm 1.63$ & $.62^{\prime}$ \\
\hline ICU stay & $\begin{array}{c}135.78 \pm 55.89 \mathrm{~h} \\
5.66 \pm 2.33 \mathrm{~d}\end{array}$ & $\begin{aligned} 159.72 & \pm 80.34 \mathrm{~h} \\
6.66 & \pm 3.34 \mathrm{~d}\end{aligned}$ & .08 & $\begin{aligned} 163.03 & \pm 54.32 \mathrm{~h} \\
6.79 & \pm 2.26 \mathrm{~d}\end{aligned}$ & $\begin{array}{r}199.87 \pm 74.2 \mathrm{~h} \\
8.32 \pm 3.09 \mathrm{~d}\end{array}$ & $.03 *$ & $\begin{aligned} 94.90 & \pm 24.88 \mathrm{~h} \\
3.95 & \pm 1.04 \mathrm{~d}\end{aligned}$ & $\begin{aligned} 88.33 & \pm 11.26 \mathrm{~h} \\
3.68 & \pm 0.47 \mathrm{~h}\end{aligned}$ & .31 \\
\hline Hospital stay, d & $12.94 \pm 0.77$ & $15.2 \pm 0.87$ & .05 & $15.7 \pm 4.77$ & $18.90 \pm 4.48$ & .01 & $8.80 \pm 3.46$ & $8.70 \pm 1.46$ & .92 \\
\hline $\begin{array}{l}\text { 30-Day } \\
\quad \text { mortality, n (\%) }\end{array}$ & 3 & 3 & 1.0 & $3(10)$ & $3(9.4)$ & .93 & 0 & 0 & - \\
\hline Arrhythmias, n (\%) & $10(20)$ & $9(18)$ & .79 & $9(30)$ & $6(18.8)$ & .30 & $1(5)$ & $3(16.7)$ & .24 \\
\hline Reintubation, n (\%) & $4(8)$ & $7(14)$ & .34 & $4(13.3)$ & 7 (21.9) & .38 & 0 & 0 & - \\
\hline Sepsis, n (\%) & $5(10)$ & $7(14)$ & .58 & $5(16.7)$ & 7 (21.9) & .60 & 0 & 0 & - \\
\hline CPR, n (\%) & $5(10)$ & $9(18)$ & .25 & $5(16.7)$ & $6(18.8)$ & .83 & 0 & $3(16.7)$ & .006 \\
\hline
\end{tabular}

Significant $P$ values are shown in bold. $C P B$, Cardiopulmonary bypass; $A O C X$, aortic cross clamp time; $L C O S$, low cardiac output syndrome; $L-0$, serum lactate level measured at completion of surgery; $L-1$, serum lactate level measured 2 hours after completion of surgery; $L-2$, serum lactate level measured 6 hours after completion of surgery; $L-3$, serum lactate level measured 24 hours after completion of surgery; $I C U$, intensive care unit; $C P R$, cardiopulmonary resuscitation. *Statistically significant with $P$ value $<.05$.

\section{Intraoperative Characteristics}

Table 2 shows the intraoperative characteristics. CPB time, aortic cross clamp times, and volume ultrafiltrate were similar in the T4 and placebo groups in total number of patients and among the patients in the subgroup.

\section{Postoperative Variables}

Postoperative characteristics are shown in Table 2. The complex and simple categories differed in this set of observations. The duration of mechanical ventilation was no different between the T4 and placebo groups. However, for the simple category, the total duration of mechanical ventilation was $11.80 \pm 1.32$ hours $(0.49 \pm 0.05$ days $)$ and $11.44 \pm 1.69$ hours $(0.47 \pm 0.07$ days; $P=.47)$ whereas in the complex category, it was $92.5 \pm 22.21$ hours $(3.85 \pm 0.92$ days $)$ and $111.81 \pm 37.30$ hours $(4.66 \pm 1.55$ days $)$ in the $\mathrm{T} 4$ and placebo groups $(P=.001)$. The serum lactate levels (Table 2$)$ were no different between the 2 groups with other subjective indicators of LCOS; this indicated that there were no differences in the prevalence of LCOS between the 2 groups $(P=.25)$. The ICU stay was no different in the entire group in the T4 and placebo groups. However, the ICU stay was longer for patients in the placebo group in the complex category (199.87 \pm 74.22 hours, $8.30 \pm 33.09$ days), compared with the T4 group (163.09 \pm 54.32 hours, $6.79 \pm 2.26$ days; $P=.03$ ). In the simple category, this difference was not observed. Similarly, the hospital stay varied between the complex and simple categories. The placebo group had a longer hospital stay $(18.87 \pm 4.48$ days $)$ compared with the thyroid group (15.70 \pm 4.77 days) in the complex category $(P=.01)$, but this difference was not observed in subgroups in the simple category. There were no statistically significant differences in morbidity indicators such as sepsis, arrhythmias, reintubation, and need for cardiopulmonary resuscitation in the thyroid and placebo groups in the complex as well as simple categories. Early hospital mortality was similar between the 2 groups.

Figures 1 and 2 show a comparison of the CI and IS of the thyroid and placebo groups, respectively. They depict the medians and 25 th and 75 th quartiles. The dots/stars denote the outliers.

\section{Measurements}

Figure 1 shows the $\mathrm{CI}$ at different time points in the total number of patients. Preoperative CI was no different in both 

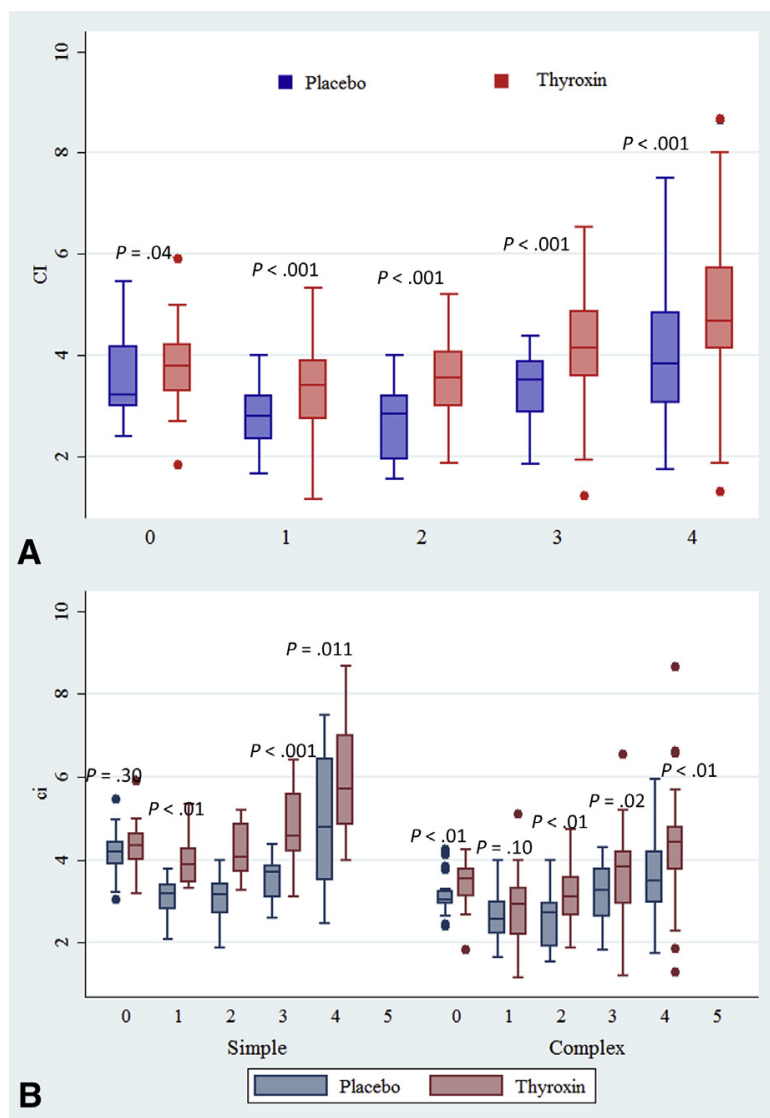

FIGURE 1. Cardiac index $\left(C I ; \mathrm{L} / \mathrm{min} / \mathrm{m}^{2}\right)$. A, Total group. B, In subgroups. $0=\mathrm{CI}$ before surgery, $1=\mathrm{CI}$ after coming off bypass, $2=\mathrm{CI}$ at 6 hours after the surgery, $3=\mathrm{CI}$ after 24 hours of surgery, and $4=\mathrm{CI}$ at 48 hours after the surgery. The upper and lower borders of the box represent the upper and lower quartiles. The middle horizontal line represents the median. The upper and lower whiskers represent the maximum and minimum values of nonoutliers. Extra dots represent outliers. Preoperative CI was not similar in both groups; it then reduced from baseline values after cardiopulmonary bypass in both groups. However, compared with the placebo group, CI was significantly higher in the thyroxin group in each subcategory after terminating cardiopulmonary bypass. A gradual increase in CI was observed in both groups over the next 48 hours, with faster recovery in the thyroxin group.

groups in each category. As expected, the CI reduced from baseline values after CPB in both of the groups. However, compared with the placebo group, CI was significantly higher in the $\mathrm{T} 4$ group in each subcategory after terminating CPB. A gradual increase in CI was observed in both of the groups over the next 48 hours, with faster recovery in the $\mathrm{T} 4$ group. The cardiac indices were significantly higher in the T4 group after surgery compared with the placebo group at all time points, showing the beneficial effects of T4. Within each severity group, $\mathrm{T} 4$ administration improved $\mathrm{CI}$ at each point. However, when the improvement in the simple group was compared with that in the complex group, there was no significant difference in the initial and the last
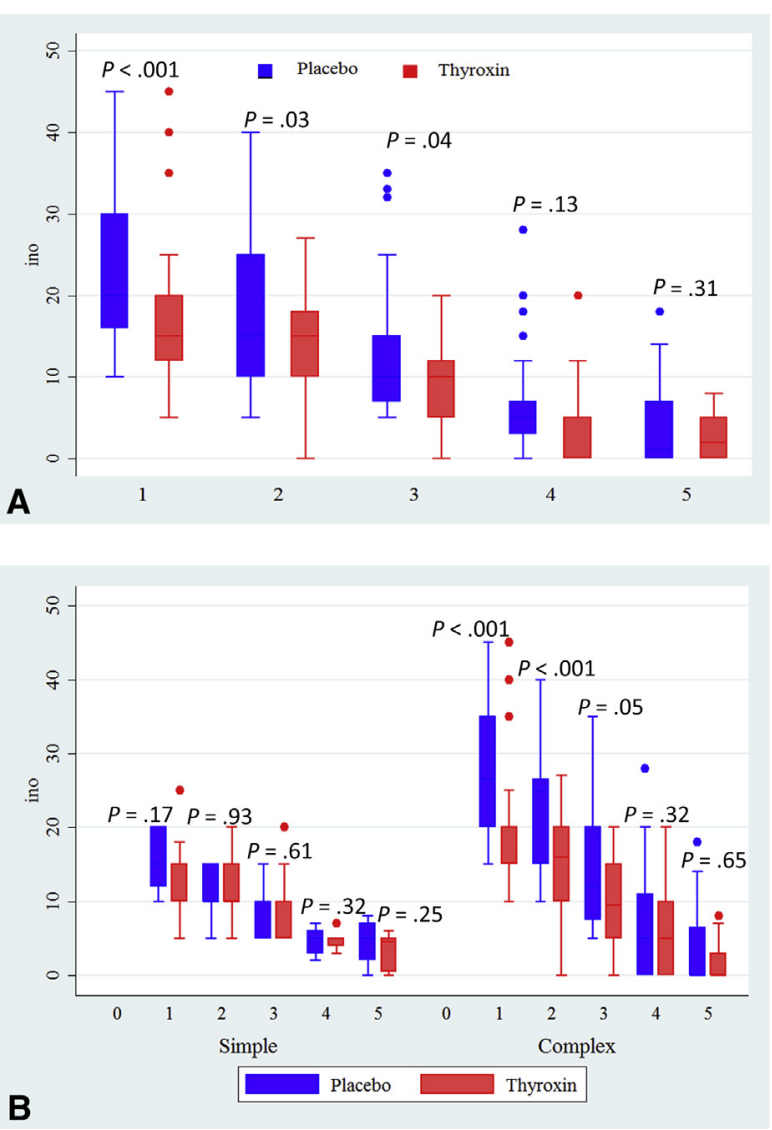

FIGURE 2. Comparison of inotropic score (ino). A, Total group. B, In subgroups. 1 = ino for the first 24 hours, $2=$ ino at $24-48$ hours, $3=$ ino at 49-72 hours, $4=$ ino at 73-96 hours, and $5=$ ino after 96 hours. The upper and lower borders of the box represent the upper and lower quartiles. The middle horizontal line represents the median. The upper and lower whiskers represent the maximum and minimum values of nonoutliers. Extra dots represent outliers. The inos were higher in the placebo group compared with the thyroxin group at all time points implying a greater need for inotropes. In the simple category, there was no statistically significant difference in the inos at any time point. However, in the complex category, the inos were higher from the initial values up to 48 hours, and later on they were not significant.

readings. CI in the $\mathrm{T} 4$ group was on an average $0.30 \mathrm{~L} / \mathrm{min} /$ $\mathrm{m}^{2}$ higher than in the placebo group at any time point $(P=.04)$.

The group versus time interaction analysis indicated that the T4 group had on an average a CI of $0.53 \mathrm{~L} / \mathrm{min} / \mathrm{m}^{2}(95 \%$ confidence interval, $0.30-0.76 ; P<.0001)$ more than the placebo group at any time point. The group versus time interaction (Figure E2) was of borderline significance $(P=.05)$ indicating that the improved effect of T4 was uniformly similar. Separate analysis for the simple group indicated an increase of $0.74 \mathrm{~L} / \mathrm{min} / \mathrm{m}^{2}(95 \%$ confidence interval, $0.51-0.98 ; P<.001)$ with no significant interaction with time $(P=.35)$. For the complex group, it indicated an increase of $0.35 \mathrm{~L} / \mathrm{min} / \mathrm{m}^{2}(95 \%$ confidence interval, 
$0.10-0.60 ; P=.005)$ with no significant interaction with time $(P=.07)$. These data indicate that the increase in CI in the total and separate groups are independent of time and remain the same.

\section{IS}

Differences in IS are shown in Figure 2. The IS was higher in the placebo group compared with the T4 group at all time points implying a higher need for inotropes. In the simple category, there was no statistically significant difference in the IS at any time point. However, in the complex category, the IS was higher from the initial values up to 48 hours, and later on they were not significant. When these differences between the simple and complex categories were compared, they were significant up to 49 to 72 hours, beyond which the simple and complex categories showed a similar response. From this, it is apparent that patients in the complex category had higher inotropic requirements in the first 48 hours after surgery whereas patients in the simple category exhibited no such differences.

Mixed interaction modeling indicated that the $\mathrm{T} 4$ group had on an average a lesser IS by 6.7 than the placebo group (95\% confidence interval, $2.7-0.7 ; P<.0001)$ at any time point. The group versus time interaction (Figure E3) was also significant $(P=.006)$ indicating that the added benefit of T4 supplementation in reducing the IS is not uniform with time. This is also shown in Figure E3, which indicates a perceptible difference up to 48 hours beyond which the differences narrow. A similar analysis for the simple group showed that the T4 group had an IS of 0.94 (95\% confidence interval, -2.1 to $4.0 ; P=.54$ ) less than the placebo group, which was statistically insignificant. The complex group showed that T4 reduced the IS by 9.5 (95\% confidence interval, 4.68-4.30; $P<.0001)$. The group versus time interaction was also significant.

\section{TISS Scores}

TISS scores were higher in the placebo group for the first 48 hours signifying intense needs for logistics and manpower for ICU care in the placebo group. Whereas no differences were observed in the simple group of patients, the TISS scores were a mean of $53.80 \pm 3.72$ versus $57.40 \pm 4.45$ in the $\mathrm{T} 4$ and placebo groups, respectively $(P<.001)$. Thereafter, no such differences were observed in either group.

\section{Serum Thyroid Hormone Levels}

Differences in serum thyroid hormone levels are shown in Figure 3. Thyroid hormone levels were decreased immediately after CPB but gradually increased serum levels of TT4 and TT3 were seen in the next 48 hours. TT4 levels were higher in the T4 group at all time points $(P<.001)$. Area under the curve for TT4 was $479.90 \pm 92.05$ in the thyroid group, which was significantly higher compared

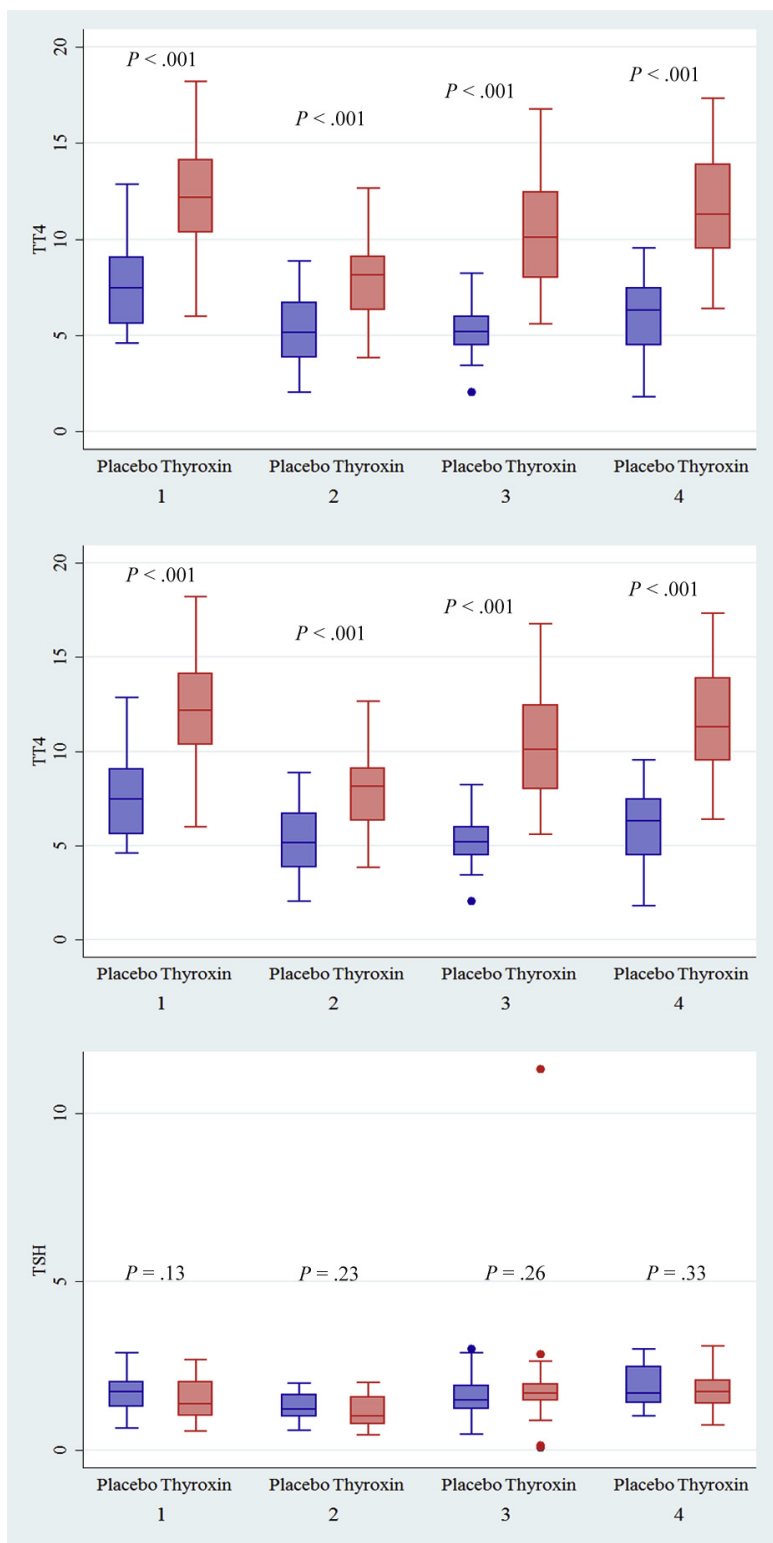

FIGURE 3. Serum thyroid hormone measurements. $1=$ before cardiopulmonary bypass $(\mathrm{CPB}), 2=$ immediately after $\mathrm{CPB}, 3=24$ hours after $\mathrm{CPB}$, and $4=48$ hours after termination of CPB. The upper and lower borders of the box represent the upper and lower quartiles. The middle horizontal line represents the median. The upper and lower whiskers represent the maximum and minimum values of nonoutliers. Extra dots represent outliers. Thyroid hormone levels were decreased immediately after CPB but gradually increased serum levels of total thyroxin (TT4) and total triiodothyronine were seen in the next 48 hours. TT4 and total triiodothyronine levels were higher in thyroxin group at all time points. However, thyroid stimulating hormone (TSH) levels showed no change.

with the placebo group, which had area under the curve of $252.15 \pm 58.95(P<.001)$. Area under the curve for TT3 was $107.34 \pm 11.21$ in thyroid group and $43.44 \pm 8.58$ $(P=.001)$ in the placebo group. Similar trends in serum 
TT4 and TT3 levels with significantly higher serum levels were observed in the $\mathrm{T} 4$ group.

\section{Inflammatory Markers}

Figure 4 shows interleukin (IL)-6 and tumor necrosis factor- $\alpha$ levels at different time points. Preoperative IL-6 levels were not statistically different between the 2 groups. In the post-CPB period, IL-6 levels were raised significantly with higher serum levels in the placebo group $(P<.001)$. These remained elevated up to 24 hours reaching toward baseline at 48 hours.

\section{DISCUSSION}

Thyroid hormones influence cardiac function by regulating the heart rate, cardiac contractility, and systemic vascular resistance. ${ }^{11}$ Surgical stress, hypoperfusion of the
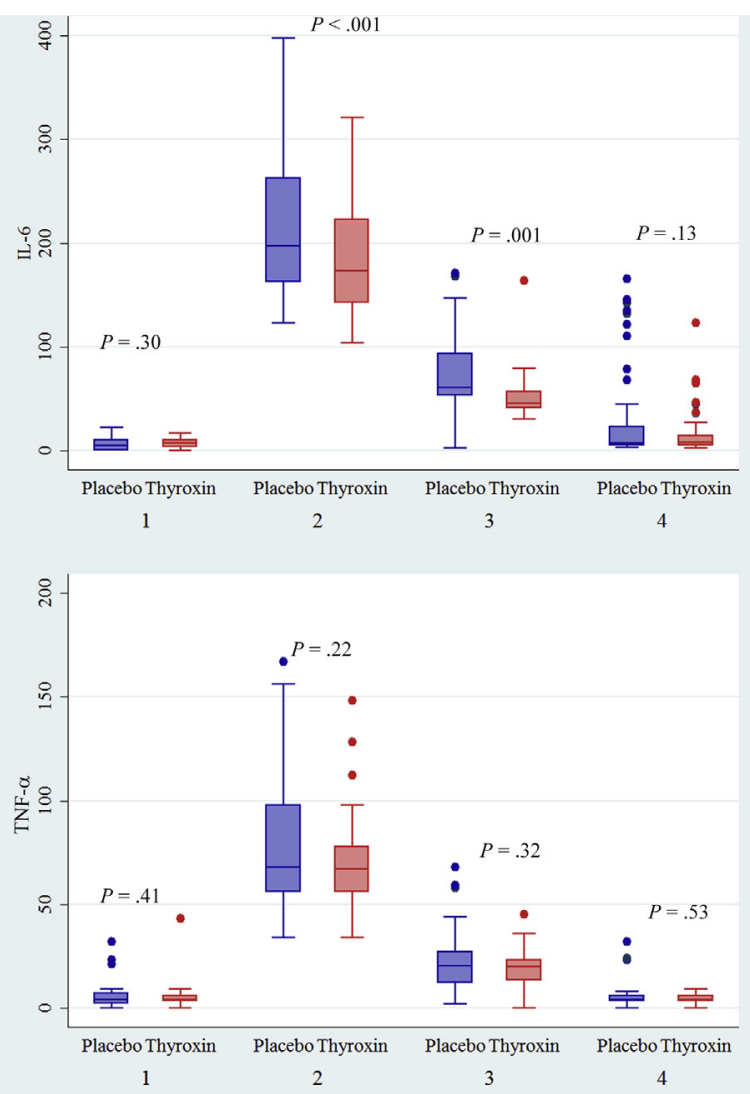

FIGURE 4. Serum inflammatory markers measurements. $1=$ Before cardiopulmonary bypass (CPB), $2=$ after CPB, $3=24$ and $4=48$ hours after surgery. The upper and lower borders of the box represent the upper and lower quartiles. The middle horizontal line represents the median. The upper and lower whiskers represent the maximum and minimum values of nonoutliers. Extra dots represent outliers. In the post-CPB period, interleukin $(I L)-6$ levels were raised significantly with higher serum levels in the placebo group. These remained elevated up to 24 hours reaching toward baseline at 48 hours. There were no changes in tumor necrosis factor $(T N F)-\alpha$ levels.

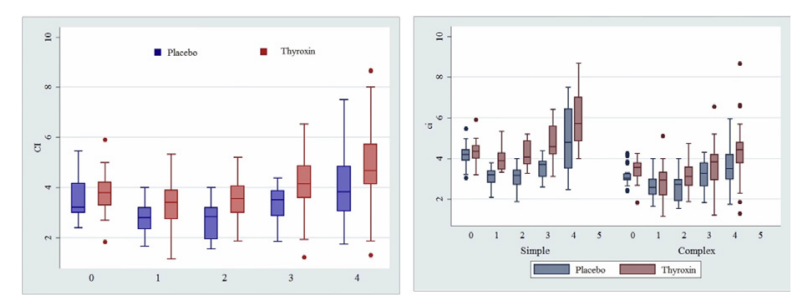

VIDEO 1. The methods and salient features of the study. Video available at: https://www.jtcvs.org/article/S0022-5223(18)31466-1/fulltext.

hypothalamus-pituitary-thyroid axis and ultrafiltration during CPB decrease serum levels of thyroid hormones in patients after open-heart surgery. ${ }^{1,3}$ This decrease has been shown to correlate with poor postoperative outcomes $^{1}$ making thyroid hormone supplementation an attractive option. Injectable forms of thyroid hormone have been proven to be beneficial in reducing mechanical ventilation, length of ICU stay, and increasing CI. ${ }^{5}$ Many randomized controlled trials $\mathrm{s}^{5,11,12}$ have been conducted to establish the role of injectable triiodothyronine in alleviating the harmful effects of thyroid hormone deficiency after open-heart surgery. In the Triiodothyronine Supplementation in Infants and Children Undergoing Cardiopulmonary Bypass (TRICC) trial children younger 2 years of age were studied and reduced time to extubation, better cardiac function, and lesser inotropic requirements were shown in infants younger than 5 months of age who received intravenous T4 in the ICU. ${ }^{5}$ Others have also shown reduced incidence of postoperative LCOS, improved myocardial function, and reduced intensive care in patients who received triiodothyronine. ${ }^{13}$ A correlation between triiodothyronine supplementation and early achievement of negative fluid has also been shown. ${ }^{11}$ All these beneficial effects are thought to translate into lower requirements of management logistics and manpower, thus lowering the cost of postoperative care. ${ }^{14}$

Bioavailability of oral forms of thyroid supplements is acceptable. Oral T4 is available as tablets of T4, that has good bioavailability and is a potential replacement for intravenous triiodothyronine infusion. Only 1 study $^{13}$ investigated oral thyroid hormone supplements in adult patients who underwent coronary artery bypass grafting and oral supplementation of $\mathrm{T} 4$ seven days before surgery and continued in the postoperative period was found to be safe with less inotropic requirement and reduced length of hospital stay. ${ }^{13}$

In developing countries where the resources are limited, cost of intensive care for infants who undergo open-heart surgery are high. ${ }^{16,17}$ Prolonged ICU stay after complex congenital cardiac surgery is an emotional and economic burden on the parents of these patients. Reports have suggested overall faster recovery in postoperative parameters with intravenous T4 administration; however, the availability and cost of intravenous triiodothyronine 
are prohibitive factors that limit its widespread usage in places where resources are limited. This stimulated us to study the effects of oral administration of $\mathrm{T} 4$ in infants who underwent open-heart surgery.

Thyroid hormones exert their action by acting on nuclear and on cell membrane receptors. Cell membrane-mediated action is immediate and occurs through sodium influx, that increases intracellular calcium to exert an inotrope-like effect. ${ }^{18-20}$ The effect on nuclear receptors is slow and involves expression of a set of genes, which increase $\alpha$ myosin heavy chain transcription. This change has been shown to occur within minutes of triiodothyronine administration in cats with a hypothyroid state. ${ }^{17}$ Transcription of $\alpha$ myosin heavy chains has been shown to peak at 12 hours after the oral administration of T4. ${ }^{18}$ Previous studies have shown decreased requirement of inotropes with the use intravenous thyroid hormone preparations. ${ }^{21}$ In our observation, the inotropic requirement was higher in the placebo group.

Oral administration of $\mathrm{T} 4$ has been shown to achieve a bioavailability of $90 \%$ to $93 \%$ compared with the intravenous route, with equal physiological actions on hemodynamics. $^{22}$ We observed that serum TT4 levels were significantly higher in the $\mathrm{T} 4$ group within 12 hours of oral administration of T4. However, after CPB, thyroid hormone levels decreased significantly in both of the groups because of ultrafiltration and effects of CPB on thyroid homeostasis. Postoperative administration of T4 maintained the $\mathrm{T} 4$ hormone levels in patients in the $\mathrm{T} 4$ group, whereas the placebo group continued to have low levels of thyroid hormones up to 48 hours after surgery. We adjusted the doses of inotropes judged according to the clinical response, using minimum inotropes in either group.

We observed higher $\mathrm{CI}$ in patients in the $\mathrm{T} 4$ group at all time points after termination of CPB, signifying the beneficial effects of the drug. Post-CPB bypass CI decreased significantly in both of the groups probably due to myocardial depression after cardioplegic arrest. However, gradual improvement was observed in both of the groups over the next 48 hours with higher $\mathrm{CI}$ in the $\mathrm{T} 4$ group compared with the placebo group. Features of LCOS as indicated by subjective parameters and rising lactate levels (as described previously) occurred equally in both of the groups between the 6 and 24 hours after surgery. However, no correlation was observed between this and thyroid hormone levels indicating that the occurrence of LCOS is multifactorial.

In this study, we included patients with complex and simple congenital heart defects, and the secondary analysis was made for these subcategories separately because these groups are expected to have different postoperative outcomes. Our results indicate that oral administration of T4 is more efficacious in the complex group of patients, but is probably not needed in the simple group. Although a matter of speculation, relatively shorter ventilation times, with less need for inotropes and manpower needs could explain this difference in the simple group.

Rapid recovery in the general condition of infants after extubation reduced the mean ICU stay in the T4 group compared with the placebo group. Again, this difference was shown only in patients in the complex category, who stayed in the ICU for a significantly longer period. A previous study has noted similar differences. ${ }^{5}$ To know the effect of T4 supplementation on the care needed to nurse these infants, we calculated the TISS for each nursing shift and computed the average scores for the first 5 days. The scores were significantly higher for the placebo group for the first 2 days in patients in the complex category. However, these scores did not differ between the T4 and placebo groups in the simple category. This signifies that babies receiving T4 needed less care in the first 48 hours compared with the placebo group. Higher TISS has been shown previously to increase the logistical requirements, manpower utilization, and prolong the ICU stay with increased costs. ${ }^{10}$

\section{Study Limitations}

Our observations suggest that oral T4 administration improves CI significantly and reduces the ICU stay and costs of care. However, this advantage might not be applicable in many centers in which fast-tracking is routinely practiced. In addition, the method adopted for measurement of $\mathrm{CI}$ by the ICON is not yet standardized in infants and children. In addition, it is a noninvasive method and cannot provide an accurate value. However, previous studies from our institute have shown the CI calculated using this method to correlate well with standard invasive methods in aduts. ${ }^{6-8}$ Larger sample size and intense tailoring of ICU protocols to individual patients rather than strict adherence to the standard protocols would show the effect of T4 supplementation in a better fashion. Moreover, the stratification of patients into complex and simple categories reduced the number of patients in each category. Therefore, a prospective randomized multicenter study including complex diagnosis is needed to better study the effectiveness of oral T4 supplementation. We did not compare the efficacy of $\mathrm{T} 4$ hormones administered through oral and intravenous routes in this subset of patients and this needs to be investigated further.

\section{CONCLUSIONS}

Thyroid hormone levels are reduced significantly in the immediate postoperative period after open-heart surgery. Oral T4 supplementation improves the CI and reduces the inotropic requirement. In addition, it reduces the duration of mechanical ventilation, ICU and hospital stay, and TISS in infants after surgery for complex congenital heart defects (Video 1). 


\section{Conflict of Interest Statement}

Authors have nothing to disclose with regard to commercial support.

This article was awarded the best abstract in the moderated poster category at the 96th Annual Meeting of The American Association for Thoracic Surgery in Baltimore, Maryland, May 2016.

\section{References}

1. Talwar S, Khadgawat R, Sandeep J, Sreenivas V, Choudhary SK, Gupta N, et al. Cardiopulmonary bypass and serum thyroid hormone profile in pediatric patients with congenital heart disease. Congenit Heart Dis. 2012;7:433-40.

2. Plumpton K, Haas NA. Identifying infants at risk of marked thyroid suppression post-cardiopulmonary bypass. Intensive Care Med. 2005;31:581-7.

3. Holland FW, Brown PS Jr, Weintraub BD, Clark RE. Cardiopulmonary bypass and thyroid function: a euthyroid sick syndrome. Ann Thorac Surg. 1991;52: 46-50.

4. Klein I, Ojamaa K. Thyroid hormone and the cardiovascular system. $N$ Engl J Med. 2001;344:501-9.

5. Portmann M, Slee A, Olson A, Cohen G, Karl T, Tong E, et al; TRICC Investigators. Triiodothyronine Supplementation in Infants and Children Undergoing Cardiopulmonary Bypass (TRICC): a multicenter placebo-controlled randomized trial: age analysis. Circulation. 2010;122(11 Suppl):S224-33.

6. Malik V, Subramanian A, Chauhan S, Hote M. Correlation of electric cardiometry and continuous thermodilution cardiac output monitoring systems. World $J$ Cardiovasc Surg. 2014:4:101-8.

7. Talwar S, Bhoje A, Sreenivas V, Makhija N, Aarav S, Choudhary SK, et al. Comparison of del Nido and St Thomas Cardioplegia Solutions in pediatric patients: a prospective randomized clinical trial. Semin Thorac Cardiovasc Surg. 2017;29: 366-74.

8. Talwar S, Murugan SS, Makhija N, Lakshmy R, Sreenivas V, Choudhary SK, et al. Effect of administration of allopurinol on postoperative outcomes in patients undergoing intracardiac repair of tetralogy of Fallot. J Thorac Cardiovasc Surg. 2018;155:335-43.

9. Gaies M, Gurney J, Yen A, Napoli M, Gajarski R, Ohye R, et al. Vasoactiveinotropic score as a predictor of morbidity and mortality in infants after cardiopulmonary bypass. Pediatr Crit Care Med. 2010;11:234-8.
10. Hariharan S, Chen D, Charles L, Bobb N, DeFreitas L, Esdelle-Thomas JM, et al The utilities of the therapeutic intervention scoring system (TISS-28). Indian J Crit Care Med. 2007;11:61-6.

11. Klemperer JD, Klein I, Gomez M, Helm RE, Ojamaa K, Thomas SJ, et al. Thyroid hormone treatment after coronary-artery bypass surgery. $N$ Engl $\mathrm{J}$ Med. 1995:333:1522-7.

12. Bettendorf M, Schmidt KG, Grulich-Henn J, Ulmer HE, Heinrich UE. Tri-iodothyronine treatment in children after cardiac surgery: a double-blind, randomised, placebo-controlled study. Lancet. 2000;356:529-34.

13. Mackie A, Booth K, Newburger J, Gauvreau K, Huang S, Laussen P. A randomized, double-blind, placebo-controlled pilot trial of triiodothyronine in neonatal heart surgery. J Thorac Cardiovasc Surg. 2005;130:810-6.

14. Chowdhury D, Ojamaa K, Parnell VA, McMahon C, Sison CP, Klein I. A prospective randomized clinical study of thyroid hormone treatment after operations for complex congenital heart disease. J Thorac Cardiovasc Surg. 2001;122:1023-5.

15. Sirlak M, Yazicioglu L, Inan MB, Eryilmaz S, Tasoz R, Aral A, et al. Oral thyroid hormone pretreatment in left ventricular dysfunction. Eur J Cardiothorac Surg. 2004;26:720-5.

16. Narang A, Kiran PS, Kumar P. Cost of neonatal intensive care in a tertiary care center. Indian Pediatr. 2005;42:989-97.

17. Talwar S, Choudhary SK, Airan B, Juneja R, Kothari SS, Saxena A, et al Reducing the costs of surgical correction of congenitally malformed hearts in developing countries. Cardiol Young. 2008;18:363-71.

18. Davis PJ, Davis FB. Nongenomic actions of thyroid hormone on the heart. Thy roid. 2002;12:459-66.

19. Wang YG, Dedkova EN, Fiening JP, Ojamaa K, Blatter LA, Lipsius SL. Acute exposure to thyroid hormone increases $\mathrm{Na}+$ current and intracellular $\mathrm{Ca} 2+$ in cat atrial myocytes. J Physiol. 2003;546:491-9.

20. Balkman C, Ojamaa K, Klein I. Time course of the in vivo effects of thyroid hor mone on cardiac gene expression. Endocrinology. 1992;130:2001-6.

21. Sharpe MD, Van Rassel B, Haddara W. Oral and intravenous thyroxin (T4 achieve comparable serum levels for hormonal resuscitation protocol in organ donors: a randomized double blinded study. Can J Anaesth. 2013;60:998-1002.

22. Zuppa AF, Nadkarni V, Davis L, Adamson PC, Helfaer MA, Elliot MR, et al. The effect of a thyroid hormone infusion on vasopressor support in critically ill children with cessation of neurological function. Crit Care Med. 2004;32:2318-22.

Key Words: oral thyroxin, infants, postoperative cardiac index 


\section{Consort diagram for thyroid study}

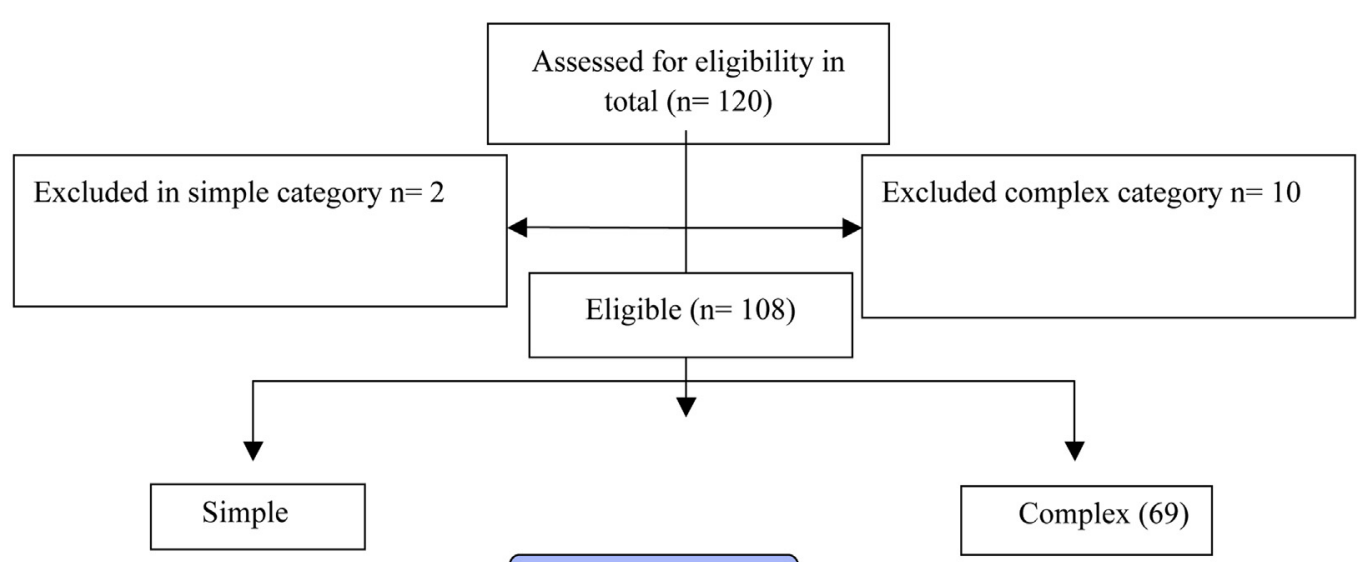

Randomized

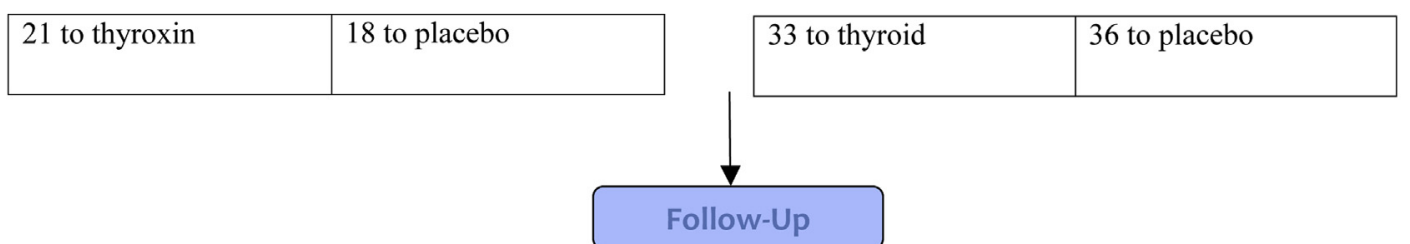

\begin{tabular}{|l|l|}
\hline $\begin{array}{l}\text { Discontinued } \\
\text { intervention } \mathrm{n}=1 \\
\text { arrhythmias }\end{array}$ & Discontinued $\mathrm{n}=0$ \\
& \\
\hline
\end{tabular}

\begin{tabular}{|c|l|}
\hline $\begin{array}{c}\text { Discontinued } \mathrm{n}=3 \\
\text { Malabsorption } \mathrm{n}=2\end{array}$ & Discontinued $\mathrm{n}=4$ \\
Failure of sampling $\mathrm{n}=1$ & Malabsorption $\mathrm{n}=2$ \\
& $\begin{array}{l}\text { Failure of sampling } \mathrm{n}=1 \\
\text { Failure to record cardiac } \\
\text { index } \mathrm{n}=1\end{array}$ \\
\hline & \\
\hline
\end{tabular}

\section{Analysis}

\begin{tabular}{|l|l|}
\hline Analysed $\mathrm{n}=20$ & Analysed $\mathrm{n}=18$ \\
\hline
\end{tabular}

\begin{tabular}{|l|l|}
\hline Analysed $\mathrm{n}=30$ & Analysed $\mathrm{n}=32$ \\
& \\
\hline
\end{tabular}

FIGURE E1. CONSORT diagram. 


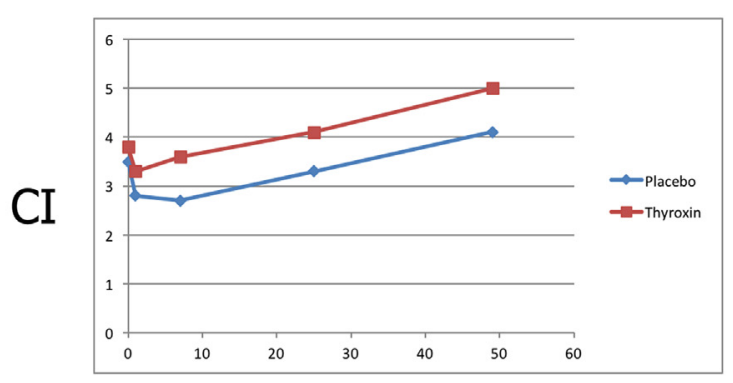

A

Time (hours)

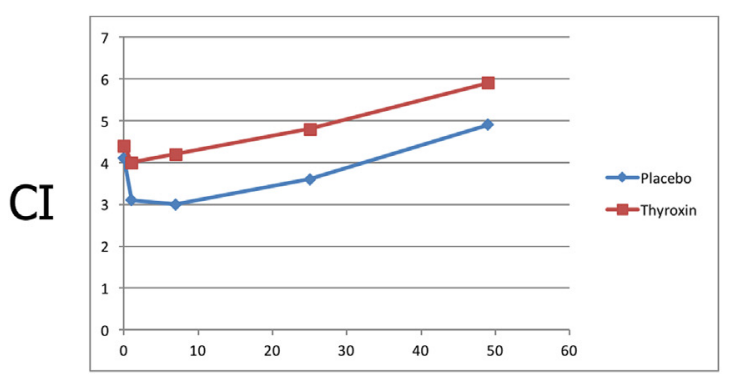

B

Time (hours)

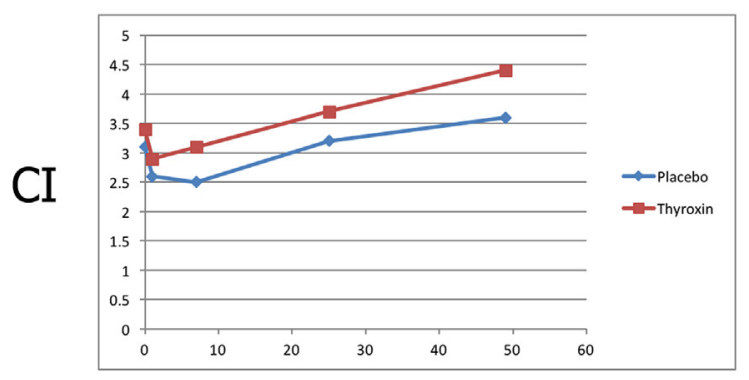

C

\section{Time (hours)}

FIGURE E2. Timewise trend of cardiac index $\left(C I ; \mathrm{L} / \mathrm{min} / \mathrm{m}^{2}\right)$ between the thyroxin and placebo group. A, for all patients; (B) for the simplex category; and $(\mathrm{C})$ for the complex category. This indicates that the thyroxin group had a higher $\mathrm{CI}$ more than the placebo group at any time point. The group versus time interaction was of borderline significance indicating that the improved effect of thyroxin was uniformly similar. Separate analysis for the simple group indicated higher $\mathrm{CI}$ in thyroxin group; no significant interaction with time. Higher CIs were also observed in the complex group, with no significant interaction with time. These data indicate that the increase in $\mathrm{CI}$ in the total and separate groups are independent of time and remain the same. 
IS

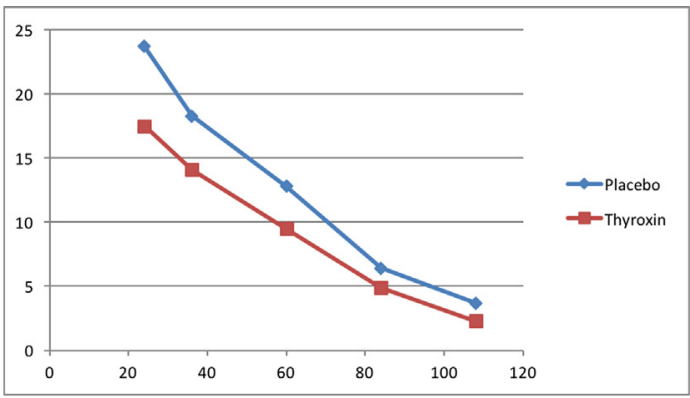

A

Time (hours)

IS

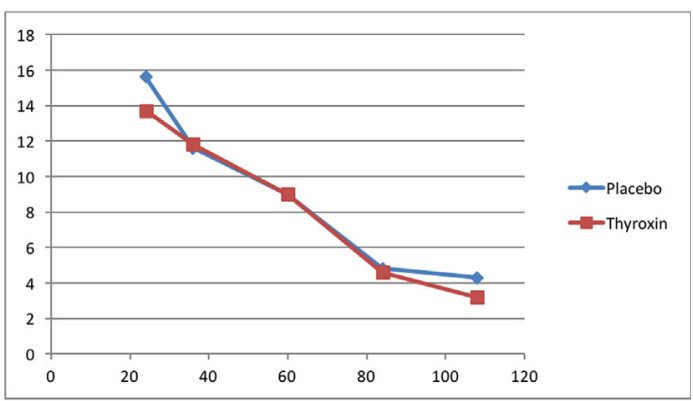

B

Time (hours)

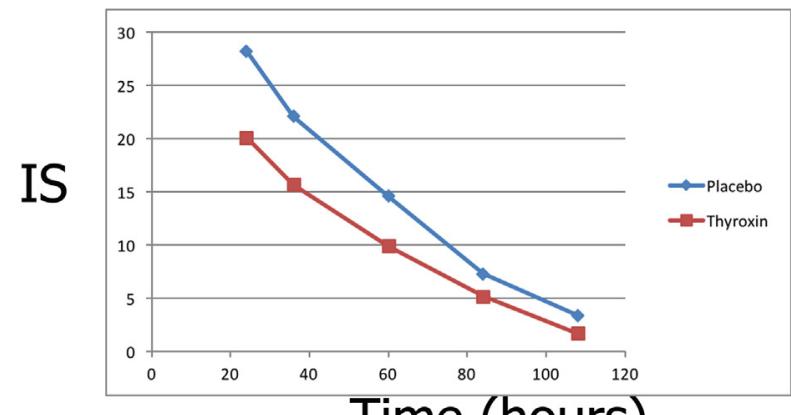

C

FIGURE E3. Timewise trend of inotropic score (IS) between the thyroxin and placebo group. A, for all patients; (B) for the simplex category; and (C) for the complex category. The thyroxin group had a lower IS than the placebo group at any time point. The group versus time interaction was significant indicating that the added benefit of thyroxin supplementation in reducing the IS is not uniform with time and narrows beyond 48 hours. 